\title{
Herpetologists' Conservation Research Focus Drives Their Intentions to Participate in Future Public Engagement
}

\author{
Kirsten A Hecht ${ }^{1}$, Kathryn A. Stofer ${ }^{2}$, Martha Monroe $^{3}$, Geraldine Klarenberg ${ }^{3}$, and Max \\ A. Nickerson ${ }^{4}$
}

\author{
${ }^{1}$ School of Natural Resources and Environment, University of Florida, Gainesville, FL 32611 \\ ${ }^{2}$ Department of Agricultural Education and Communication, University of Florida, Gainesville, FL \\ 32611 \\ ${ }^{3}$ School of Forest, Fisheries, and Geomatics Sciences, University of Florida, Gainesville, FL \\ 32611 \\ ${ }^{4}$ Florida Museum of Natural History, University of Florida, Gainesville, FL 32611
}

\section{Abstract:}

Public Engagement with Science (PES) is a popular topic in the science community due to general concerns about public support for science, attitudes toward science, and changes in scientific funding requirements. PES may be especially relevant in conservation disciplines as the public plays an important role in conservation practice. Herpetofauna specifically stand to benefit, as PES activities can help improve attitudes and conservation behavior of participants toward uncharismatic species. We assessed the current scope of herpetologists' PES activities and investigated factors associated with their participation in PES. We used a closed-ended question survey distributed via the listservs of four American herpetological organizations. Herpetologists' intentions to engage at least 10 hours in the next 12 months significantly differed between herpetologists with high and low conservation research focuses, but hours of engagement in the past 12 months was not significantly different among these groups. Despite most responding herpetologists having limited formal training, time, resources, and institutional support, many participated in a variety of PES activities, often utilizing partnerships and their own resources. Sampled herpetologists rarely evaluated their PES activities or considered publishing about their engagement activities. Some respondents expressed unease with the idea of message framing. Respondents were interested in evaluation training and providing accessible opportunities, and grant funds were the most likely interventions to increase herpetologists' participation in PES. These results provide reference data and insight into the public engagement practices and needs of practicing herpetologists and conservation scientists.

\section{Keywords: Public engagement, Science communication, Human Dimensions, Community} Engagement 
Author statement: We informed participants of their rights and protections as approved by University of Florida IRB201800258. None of the authors have conflicts of interest related to this research. Funding for the research was provided by a Roger Conant Grant from the Society for the Study of Amphibians and Reptiles (SSAR). SSAR had no role in interpretation of data, the writing of the report, or the decision to submit the article for publication.

\section{Introduction}

As a field, conservation biology is intimately tied with public interest. Wildlife conservation efforts based on biological scientific knowledge and solutions alone are often unsuccessful at meeting conservation goals (Agrawal and Gibson, 1999; Knight et al., 2006; Mascia et al., 2003; Meffe, 2002; Wilson et al., 2007) and there have been repeated recent calls to not only include, but to make social factors a key aspect of conservation (Ban et al., 2013; Bennett et al., 2017; O’Donnell \& Durso, 2014; Saunders et al., 2006; Wake, 2008b). Mascia et al. (2003, p. 649) expressed the essence of this shift in the following passage, "Although it may seem counterintuitive that the foremost influences on the success of environmental policy could be social, conservation interventions are the product of human decision-making processes and require changes in human behavior to succeed." Public engagement with science (PES), which the “intentional, meaningful interactions that provide opportunities for mutual learning

61 between scientists and members of the public," (AAAS, 2021; para. 1) is one tool that could bridge between these ecological and socio-ecological factors, potentially serving to increase public support for policy and conservation activities. 
wildlife field. Reptiles and amphibians in particular face unique conservation challenges when compared to other organismal groups. Herpetofauna continue to decline in number with researchers now estimating that over $40 \%$ of the world's studied amphibians (IUCN, 2018) and $20 \%$ of studied reptiles (Böhm et al., 2013) are threatened with extinction worldwide while also facing localized decreases in occupancy and metapopulations (Adams et al., 2013; Grant et al., 2016). Herpetofaunal conservation also faces challenges from deep social and cultural barriers including attitudes, social values, and norms (Alves et al., 2012; Ceríaco, 2012; Ceriaco et al.,

74 2011; Perry-Hill et al., 2014; Tarrant et al., 2016), negative emotions such as disgust (de Pinho et al., 2014; Gunnthorsdottir, 2001; Knight, 2008), and even innate fear (Hoehl et al., 2017; LoBue and DeLoache, 2008), which ultimately lead to high rates of persecution, less public support for conservation, and less priority in regards to research and conservation attention and funding (Bonnet et al., 2002; Clucas et al., 2008; Gratwicke et al., 2012).

Public engagement activities provide an opportunity for herpetologists to increase

81 conservation support for reptiles and amphibians among the public. Interventions focused on general knowledge (i.e., one-way communication) or simple exposure, such as watching snakes in a zoo, have not shown significant changes in attitudes towards herpetofauna (Prokop and Tunnicliffe, 2010; Tomažic, 2011), or changes in values or behavior (Morgan and Gramann,1989). In contrast, positive interactive experiences with snakes, specifically direct contact (Prokop and Tunnicliffe, 2010) and modeling, where

87 individuals can see others positively interacting with animals (Morgan and Gramann, 88 1989), were most effective at eliciting changes in participants, particularly when 
information was included as part of the experience. Even limited one-day exposures, such as field trips where students were able to handle and measure animals, altered likeability and individual support for conservation of snakes and salamanders (Morgan \& Gramann, 1989; Reynolds et al., 2018). Programs utilizing a full treatment set (exposure, knowledge, modeling, and direct contact) may have the highest success. A citizen science program in India, for example, reduced human persecution of snakes in the area and improved attitudes of participants towards snakes (Balakrishnan, 2010). Ultimately these types of activities may help change attitudes about uncharismatic species because they foster familiarity with the groups or species and can even change aesthetic beliefs and attitudes which has been linked to increased positive attitudes towards species (Jimenez and Lindemann-Matthies, 2015; Reimer et al., 2014). public. For example, a Pew Research Report found that scientists who felt the public had more interest in their research area were more likely to engage (Pew Research Center, 2015). In that same study, scientists who felt there was controversy in their fields were more likely to talk to reporters and citizens as well as use blogs and social media when compared to scientists who rarely or never saw debate about their field in the public eye (Pew Research Center, 2015). In another study of 1,254 biomedical scientists, Dudo (2012) found that respondents who believed that publicly public activities. However, it is unclear whether conservation sub-fields follow this trend. 
112 limited study on the broader public engagement activities of conservation biologists

113 focused on reptiles and amphibians. During a literature review, we found only limited

114 examples of publications related to education and outreach in any U.S. based

115 herpetological journal over the past 20 years (Clancy et al., 2021). These publications

116 largely focused on herpetology courses in formal education settings or museums

117 (Chiszar, 1998; Frost, 1998) and citizen science from a data collection perspective

118 (O’Donnell and Durso, 2014; Weber et al., 2016). A handful described education and

119 conservation outcomes for a variety of audiences including herpetological educators, K-

12012 teachers, and children (Ballouard et al., 2012; Gangloff, 2011; Rommel-Crump et al.,

121 2016; Wojnowski, 2008). A non-peer reviewed report found surveyed individuals in all

122 sectors of herpetology, including hobbyists, participating in public outreach activities,

123 specifically helping run or organize public education programs alone or on behalf of

124 herpetological societies (Southwestern Center for Herpetological Research, 2017).

125

126

127

128

129

130

131

132

133

134

135
Many of the surveyed recreational and professional herp-enthusiasts have attended or

facilitated some type of educational activity. There is no additional research to our knowledge specifically related to public engagement by herpetologists, including whether herpetologists whose research focuses primarily on conservation are more likely to engage with the public due to a higher public interest factor. Therefore, we surveyed herpetologists regarding their public engagement activities and experiences

as a case study to help improve the effectiveness of public engagement as a tool for the conservation of uncharismatic animals. The objectives of this study were to determine:

1. The types of engagement activities in which herpetologists participate;

2. How prepared herpetologists are to engage with the public;

3. The barriers herpetologists face to engage with the public; and 
4. Whether herpetologists' professional interest in conservation is a significant predictor of their public engagement participation.

\section{Methods}

\section{Population of Interest}

The population of interest for this study is herpetological researchers, ages 18 and over, who reside in the United States. We defined herpetological researchers as individuals who conduct original scientific herpetological research and have published at least one related peer-reviewed paper in a scientific journal. The population encompassed herpetologists from all potential sectors, including, but not limited to, universities, zoos, government agencies, museums, non-governmental organizations, and private industry, and contained herpetologists with varied levels of herpetological related conservation research.

\section{Survey Instrument}

We developed a survey consisting of 37 closed-ended questions which was based on our research questions as well as results from fifteen semi-structured interviews (Hecht, 2021). Questions covered demographics; herpetology research interests; how often conservation was a focus of their work; study animals; and public engagement knowledge, training, and practices. The survey had four screening questions that asked if respondents fit the criteria of our population of interest (residing in United States, 18 or older, conducted original research on reptiles and/or amphibians, and have published at least one peer-reviewed paper on reptiles and amphibians) and a general question about what types of publicly oriented activities they had participated in within the last 12 months. Following these questions, we provided the AAAS definition of public engagement with science as "intentional, meaningful interactions that provide 
opportunities for mutual learning between scientists and members of the public." (AAAS, 2021; para. 1) We measured level of participation in public engagement by asking about the frequency of their participation in the last 12 months as well as their intention to participate in the next 12 months. To quantify past engagement, participants were asked to choose categories corresponding to how many hours of herpetology related public engagement they participated in as an expert within the last 12 months (I did not engage, $<10,10-49,50-99$, and >100). Future participation was measured from two 7-

167 point bipolar adjective scale questions (Ajzen, 2006) which measured their intention to participate in at least 10 hours of public engagement over the next 12 months: 1) I intend to participate in public engagement as a herpetology expert for at least 10 hours

170 in the next 12 months (highly likely to highly unlikely), and 2) I will try to participate in

171 public engagement as a herpetology expert for at least 10 hours in the next 12 months

172 (definitely will not to definitely will).

174 public engagement, and/or herpetology fields reviewed the survey in two rounds. We

175 then pilot tested the survey with two students and four professionals affiliated with

176 environmentally related fields that would be familiar with the terminology, but not within

177 our specific population of interest, i.e., non-herpetologists, to maximize the number of

178 people we sampled, as most herpetologists would receive the survey through their

179 professional organizations. After each round, participants sent us either verbal or written 180 feedback, and we incorporated their feedback into the survey. The survey was entered 181 into Qualtrics prior to distribution. 


\section{Recruitment}

We sent the final Qualtrics survey link to members of four North American herpetological societies and organizations to share via an anonymous link sent through their membership listservs and newsletters: Partners in Amphibian and Reptile and Reptiles (SSAR) (1,613 members), Herpetologists' League (HL) (599 members in 2015), and the American Society for Ichthyologists and Herpetologists (ASIH) $(1,517$ members with approximately half identifying as herpetologists). The survey was open was eligible to receive a $\$ 10$ prepaid debit card by providing their email in a separate survey provided upon the competition of their survey.

\section{Analysis}

Prior to analysis, we converted the 7-point bipolar scales of the intention questions to integers ranging from -3 to 3 and added the two intention questions together to obtain a composite score for each participant. We checked all variables for normality and collinearity prior to analysis. A correlation of greater than 0.6 between predictor variables was used as the cut off value for determining multicollinearity (Dormann et al., 2013). We used basic descriptive statistics to analyze survey data for

200 all objectives. To determine if herpetologists working in the conservation biology 201 subfield were more likely to engage with the public, we analyzed subfield data and conservation focus of research data using ordinal regression analysis. We used a 203 backward stepwise model building approach using Akaike Information Criterion (AIC) 204 estimates to determine the best fit for each individual model (Akaike, 1998). We also 205 examined whether the level of conservation focus of respondents impacted their 
engagement activities. Due to the low response count in the never category $(n=8)$, responses to the question regarding the amount of research related to herpetological conservation was transformed from 5 choices (Never $(n=8)$, Less than half the time $(n=47)$, About half the time $(n=23)$, More than half the time $(n=45)$, and Always $(n=55)$ to 3 categories (Low $(n=55)$, Medium $(n=23)$, and High $(n=100))$ prior to analysis. We hypothesized that individuals who had a high conservation focus in their research would a) have participated more hours in public engagement activities in past 12 months and b) would also exhibit a higher intention to participate in public engagement for at least 10 hours in the next 12 months. Due to the lack of normality in the data, we conducted a non-parametric Kruskal-Wallis test to look for differences among the three conservation focus categories to test our hypotheses. We then conducted a post-hoc pairwise comparison using a Dunn test with a Bonferroni correction. All significance tests used an alpha value of 0.05 .

We analyzed all data using $R$ ( $R$ Core Team 2020). We conducted ordinal regression analysis using the polr and StepAIC functions in the MASS R package (Venables \& Ripley, 2002); We used the FSA R package (Ogle et al., 2020) to conduct the Dunn test. All other stats were analyzed through the base stats program of R.

\section{Results}

A total of 355 unique individuals started the survey, of which 217 were eligible participants that passed the four screening questions. Of those respondents, 178 completed the full survey. Due to disseminating the survey through professional associations and overlapping memberships, it was not possible to calculate a population size or response rate. Estimated survey time from Qualtrics was 17.4 minutes and pilot testers took between 14 and 43 minutes. Only 12 study participants took longer than 1.5 
230 hours to complete the survey. The mean survey duration for the remaining 166

231 participants was $21.15 \pm 13.00$ minutes.

\section{Demographics}

Demographics matched findings of other demographic surveys of herpetology organizations (2019 Diversity Survey Report, 2020; Demographic and Atmospheric Survey, 2020). Participants included representatives from all adult age categories with $57.9 \%$ coming from two age classes (25-34 and 35-44 years; Figure 1). Most survey takers self-identified as men (58.4\%), with the remaining participants identifying as women (38.8\%) and non-binary/third gender (1.1\%). A small number (1.7\%) preferred not to disclose their gender. Of the participants, 7.3\% identified as Hispanic, Latino, or Spanish Origin. Most participants (89.9\%) described their race as white, while 1.7\% and described themselves as multi-racial.

Respondents ranged across experience levels, but $41.0 \%$ had been in the field

244 for at least 20 years. Most participants had an advanced degree with 55.6\% holding

245 some type of doctoral degree, $34.3 \%$ holding a master's degree, $8.4 \%$ having a bachelor's degree, and $1.7 \%$ having a high school diploma as their highest education level. Participants had expertise in a variety of sub-fields, with many selecting multiple sub-fields to describe their research. The number of identified sub-fields per participant

250 the most frequently selected categories with over $70 \%$ of participants identifying either

251 of them as a sub-field of their research. Behavior (42\%) and Evolution (40\%) were the

252 next most frequently reported sub-fields. Participants also represented a variety of 
254 undergraduate- and graduate-serving institutions represented the highest percentage of

255 individuals, over $30 \%$ of the sample participants, followed by agencies (22\%), and

256 museums (10\%). One out of five respondents reported themselves as students. Survey

257 takers represented all four of the organizations surveyed: ASIH (54.5\%), HL (44.4\%),

258 SSAR (70.2\%), and PARC (49.4\%). Many individuals were members of multiple

259 societies, with respondents belonging to a mean of $2.19 \pm 1.10$ societies and $11.8 \%$ of

260 respondents belonging to all four. In addition, $27.0 \%$ of responding herpetologists

261 belonged to a regional herpetological society and $11.2 \%$ identified as members of a

262 local herpetological organization.

263

264

265

266

267

268

269

270

271

272

273

274

275

276

277

\section{Objective 1: Types of Activities}

Almost all (98\%) of those surveyed had participated in public engagement activities as a herpetology expert, and $36 \%$ of respondents reported public engagement was part of their job duties. Within the last 12 months, $67.5 \%$ of participants reported they had participated in at least 10 hours of public engagement activities, with $52.2 \%$ citing $10-49$ hours and $10.2 \%$ reporting 55-99 hours of public engagement activities in the same period. Only $3.6 \%$ of respondents did not participate in any public engagement activities as a herpetology expert in the last 12 months. Half of the participants also had high levels of intention to participate in at least 10 hours of public engagement in the next 12 months with $47.8 \%$ expressing they were both highly likely to participate and also intended to participate at this level.

Respondents were more likely to develop their own engagement programs at least sometimes (85.2\%) rather than participate in an already established program (62.5\%). All but $6.5 \%$ of participants parterned in at least one stage of engagement, with $37 \%$ partnering during activity development and $48 \%$ for implementation. Only $14 \%$ of 
278 respondents never use live animals in their engagement activities, while $35.2 \%$ and

$27918.2 \%$ use them sometimes and always, respectively. The number of public-oriented

activity types that respondents were involved with over the past 12 months ranged from

281

zero to fifteen with a mean of $4.65 \pm 3.06$. In-person lectures for the public, social

282

media, and citizen science were the three most common public-oriented activities

(Figure 2). Virtual lectures, blogs, science cafés, and teacher trainings were the least reported activities.

\section{Objective 2: Training and Knowledge}

Approximately two out of three participants (67.6\%) stated they had never had (16.9\%), knowledge tests (7.9\%), interviews (5.1\%), social media metrics $(11.8 \%)$, 
302 were the next two most popular training choices. About one in five $(21.9 \%)$ of respondents were not interested in additional training.

\section{Objective 3: Barriers}

Participants cited limited time (74.3\%) as the most common factor that at least

312 cited the most often (25.8\%) followed by more engagement opportunities (23.0\%) and dedicated work time (22.5\%). Work-related recognition (9.6\%), potential for publications

315 participants engage with the public more often.

\section{Objective 4: Impact of Conservation}


325 Figure 3). In follow-up pair-wise comparisons using a Dunn's Test, we found a

326

327

328

329

330

331

332

333

significant difference between the low and high conservation groups regarding intention

to participate in at least 10 hours of public engagement in the next 12 months $(Z=2.42$, $\mathrm{p}$-value $=0.049)$. Following Bonferroni correction, we did not find a significant difference between medium and high levels of conservation focus $(Z=2.0433, p$-value $=0.123)$. We found that sub-fields were not significant predictors of future intentions to engage at least 10 hours over the next 12 months, but conservation biology, taxonomy, behavior, and education were significant terms in the ordinal logistic regression predicting how many hours over the past 12 months respondents engaged with the public (Table 1; Table 2).

\section{Discussion}

Overall, we found that respondents were generally involved in public engagement activities, with less than $4 \%$ not participating in the past year. Similar patterns of general support and participation in public engagement activities have been noted in both general populations of scientists (Pew Research Center, 2015; Royal Society, 2006), as well as specific fields, such as particle physics (Rao, 2016); but not biology and physics professors at top research universities, where only $58 \%(n=150)$ of respondents were involved in science outreach (Ecklund et al., 2012). The Pew Research Center report (2015) also noted a similar pattern of engagement levels to our study, with the most responding scientists fitting in the "occasional participation" level (49\%) as compared to our $52.2 \%$ participating in 10-49 hours in the past 12 months. We also found that herpetologists were participating in some specific activities with potential for two-way communication at similar rates to scientists in other studies. For example, our study found that respondents used social media (56\% vs 47\%) and 
349 participated in policy making (20.7\% vs $16 \%)$ at slightly higher rates than those in the AAAS study (Pew Research Center, 2015). Herpetologists in our study volunteered in schools $(29.8 \%)$ more often than AAAS scientists $(20 \%)$, but less often than biologists and physicists at top research universities (32\%; Ecklund et al., 2012). Our respondents blogged less often than AAAS scientists (8.2\% vs $24 \%$ ). The small differences found

354 between studies could be due to temporal changes such as an increase in general support for public engagement activities, federal funding for broader impacts, or a decrease in the popularity of written blogs since the 2015 AAAS study. interest related to their field may help explain some of the patterns we found in this study, but additional factors related to wildlife outcomes may also encourage herpetologists to engage. Wildlife conservation is intimately tied to broader societal processes including socioeconomic factors, policy, and cultural norms; the field is directly tied to public interest. Therefore, we expected herpetologists who participated in conservation research to have higher levels of intention to participate in engagement activities. As we hypothesized, engagement intentions differed significantly in responding herpetologists based on their level of conservation focus in their own research. In addition, reporting conservation biology as one of their sub-fields was a 367 significant predictor of how many hours herpetologists had engaged in public 368 engagement in the last 12 months. While public interest is one possible explanation for the greater intentions seen among more conservation-oriented herpetologists, public

370 opinions of reptile and amphibian conservation may also play a role. During qualitative 371 interviews, we found that herpetologists' interest in conserving herpetofauna is often 
372 tied to societal beliefs and the public's negative attitudes toward and persecution of

373 herpetofauna (Hecht, 2021). Thus at least for conservation-oriented herpetologists,

374 scientific engagement activities appear to be driven in part by herpetofauna welfare

375 rather than public interest. Thus, the influence of public interest on scientists'

376 engagement levels may expand beyond how much scientists feel the public is

377 interested in their field to include how much the public impacts or is integrated with a 378 scientist's field of study.

Another finding of this study is that factors measuring the conservation focus of respondents' research were not consistent in their predictive powers when comparing herpetologists' future engagement intention to participation in the past 12 months. For example, a high level of conservation focus in research was associated with a higher intention to participate in engagement within the next 12 months, but did not result in

384 higher levels of engagement within the past 12 months. In contrast, selection of conservation biology as a relevant sub-field of their research was a significant predictor of herpetologists' engagement activity over the past 12 months, but not of their future

387 intention to engage. In addition, taxonomy, behavior, and education were also significant predictors of future intenion. While this could suggest that barriers are

389 preventing some individuals from participating at levels they would like to, alternative explanations are also likely. These sub-field findings may be due to survey design

391 considerations for example, as respondents were able to report all sub-fields that they 392 participate in, rather than only their main sub-field. Impacts of job sector may also be at 393 play, as taxonomy is a common field of study associated with museums which often 394 have a public mission focus. 
While our survey respondents represented the overall demographics of herpetologists, ecology and conservation sub-fields may have been over-represented in our survey response. Since there are no data available about representation of sub-

398 fields in herpetology, the implications of this to the results of our study are unclear. As those with a focus in conservation may be more likely to intend to participate or

400 ultimately participate in public engagement based on the results of our study, one 401 concern is that this finding suggests self-selection bias in our respondents toward those 402 with increased interests in public engagement. Self-selection bias describes a sampling error where a certain sub-group of your population of interest, in this case those who

405 those in other sub-groups, affecting survey results (Heckman, 1990; Whitehead, 1991).

406 Despite these concerns, however, our respondents represented a normal distribution of 407 actual participation in public engagement activities over the past 12 months. While this 408 finding does not erase the possibility of self-selection bias based on interest, it does 409 suggest that our results remain valid and still represent the spectrum our target 410 population regarding their experiences with public engagement.

\section{Recommendations:}

We found that most respondents were already regularly engaging with the public with over $2 / 3$ of respondents regularly engaging at least 10 hours of engagement

414 activities over the last 12 months. Respondents also reported high levels of intention to 415 participate in public engagement over the next 12 months, despite noted barriers. Public engagement seems to be generally accepted and valued by our respondents. However,

417 the discrepancies noted between intention to engage and actual past activity as well as 
419 herpetologists are interested in participating in public engagement activities more often 420 than they are able. Therefore, we recommend that individuals and organizations with an

421 interest in supporting public engagement activities focus on reducing the following key

422 barriers and increasing awareness of engagement best practices to interested

423 individuals.

$424 \quad$ Most of these respondents have not received training in public engagement skills

425 or strategies, and many are interested in increasing their knowledge of best practices.

426 Increasing herpetologists' use of public engagement best practices may hold unique

427 challenges since herpetologists may largely be unaware of the existence or importance

428 of engagement best practices. Only a third of respondents received any type of training

429 for conducting public engagement and most rarely or never consulted peer-reviewed

430 literature or other resources to improve their engagement knowledge or skills. While

431 these findings suggest that herpetologists may not be fluent in the language of public

432 engagement, most respondents are doing something, suggesting that these

433 respondents are not being prevented from engaging due to their lack of training or

434 knowledge. However, the low use of some best practices, especially evaluation, shows

435 that there is room for improvement in engagement practices, and it is unclear how

436 effective their engagement practices may be. Therefore, one of the first challenges is to

437 promote public engagement as a skill or sub-field much like other emerging

438 conservation tools in herpetology such as structured decision making (Gregory et al., 439 2012).

Tempering these potential challenges in understanding and improving 
442 learning more despite feeling it was unnecessary for their participation. Four out of five

443 of herpetologist surveyed expressed interest in receiving some type of engagement

444 training. Even more promising is that those responding expressed the most interest in

445 receiving engagement training which also represented was one of the identified problem

446 areas we found in our survey. Therefore, providing training opportunities in evaluation,

447 developing engagement programs, and holding difficult conversations will likely receive

448 interest, provided participants experience minimal time and money barriers to access

449 these professional development opportunities. Providing these professional

450 development opportunities at herpetology conferences or virtually may be one

451 opportunity. Another option, due to the already strong culture of partnering for

452 engagement opportunities, is to instead focus on connecting herpetologists to partners

453 with expertise in these areas of interest to provide support.

Our last recommendations focus on reducing the barriers of time and money to

455 allow herpetologists who wish to engage the opportunity to do so at their desired level.

456 Herpetology and conservation organizations should consider developing funding

457 opportunities designed to directly fund related engagement. Respondents were also

458 interested in more engagement opportunities (23.0\%), suggesting they may not be

459 aware of already existing possibilities to participate. Conservation and herpetological

460 organizations could focus on providing resources to connect herpetologists to public

461 engagement opportunities and partnerships to increase the frequency and quality of

462 engagement activities. Lastly, since most respondents were using their own resources

463 to conduct engagement, employers interested in supporting their employee's public 
464 engagement activities could allow some fraction of work time to be used for engagement activities or provide other resources.

Future research should further examine how much herpetologists are already

467 utilizing best practices, especially for their desired goals. While our results show a few

468 glaring issues with engagement best practices in herpetology, especially regarding

469 evaluation, other best practices such as using live animals or adjusting messages to an

470 audience were reported as being regularly utilized. However, since these questions

471 were asked generally, and herpetologists may not share the same understanding of

472 how to put these suggestions into practice, a more thorough investigation is necessary

473 to know how to improve usage. For example, other studies have found that scientists

474 frequently use a knowledge deficit model when communicating with the public (Davies,

475 2008), despite studies that suggest this model generally does not lead to positive

476 outcomes in science communication or public engagement goals. If herpetologists are

477 indeed adjusting their message based on their audience but only doing so in certain

478 ways, like avoiding jargon, their approaches still largely focus only on transferring

479 scientific knowledge to their audience, which may not necessarily lead to the positive

480 outcomes best practices strive for.

While we recognize our results focus on herpetologists as a case study, we

482 anticipate that these findings and recommendations may be more universally applicable

483 in the conservation field, especially for individuals studying organisms or ecosystems

484 that receive less conservation attention than charismatic animals, which generally

485 receive more support for conservation both from the public and from within the

486 conservation field itself (Clucas et al., 2008; de Pinho et al., 2014). Future research 
should investigate engagement in related sub-fields that have a natural resource and/or conservation focus to determine if our findings are unique to herpetology or are similar across related sub-fields. Specifically, these studies should compare sub-fields with more charismatic animals, like ornithology and mammalogy, with those sharing typically uncharismatic animals like entomology and shark biology. Comparisons of scientists working in basic ichthyology with those working in fisheries science, a sub-field with a long history of public involvement due to the recreational, economic, and subsistence nature of the field, could also provide additional insight on how public views of the study animal and the importance of the public in the field may influence scientists' participation in public engagement.

\section{CRediT author statement}

K. Hecht: Conceptualization, Methodology, Software, Formal Analysis, Investigation, Data Curation, Writing -Original Draft Preparation, Funding Acquisition ; K. Stofer: Conceptualization, Methodology, Writing-Review \& Editing, Supervision, Project

Administration; M. Monroe: Conceptualization, Methodology, Writing-Review \& Editing, Supervision; G. Klarenberg: Software, Formal Analysis, Writing-Review \& Editing; M.

Nickerson: Conceptualization, Writing-Review, Supervision.

\section{Diversity Survey Report, 2020. ASIH Diversity and Inclusion Committee.}

AAAS, 2021. Why Public Engagement Matters [WWW Document]. American Association for the Advancement of Science. URL https://www.aaas.org/resources/communicationtoolkit/what-public-engagement (accessed 1.4.21).

Adams, M.J., Miller, D.A.W., Muths, E., Corn, P.S., Grant, E.H.C., Bailey, L.L., Fellers, G.M., Fisher, R.N., Sadinski, W.J., Waddle, H., Walls, S.C., 2013. Trends in amphibian occupancy in the United States. PLoS ONE 8, e64347. https://doi.org/10.1371/journal.pone.0064347 
Agrawal, A., Gibson, C.C., 1999. Enchantment and disenchantment: The role of community in natural resource conservation. World Development 27, 629-649. https://doi.org/10.1016/S0305-750X(98)00161-2

Ajzen, I., 2006. Constructing a theory of planned behavior questionnaire. Amherst, MA. Akaike, H., 1998. Information theory and an extension of the maximum likelihood principle. Selected Papers of Hirotugu Akaike, Springer Series in Statistics 199-213.

Alves, R.R.N., Vieira, K.S., Santana, G.G., Vieira, W.L.S., Almeida, W.O., Souto, W.M.S., Montenegro, P.F.G.P., Pezzuti, J.C.B., 2012. A review on human attitudes towards reptiles in Brazil. Environmental Monitoring and Assessment 184, 6877-6901. https://doi.org/10.1007/s10661-011-2465-0

Balakrishnan, P., 2010. An education programme and establishment of a citizen scientist network to reduce killing of non-venomous snakes in Malappuram district, Kerala, India. Conservation Evidence 7, 9-15.

Ballouard, J.-M., Provost, G., Barré, D., Bonnet, X., 2012. Influence of a Field Trip on the Attitude of Schoolchildren toward Unpopular Organisms: An Experience with Snakes. hpet 46, 423-428. https://doi.org/10.1670/11-118

Ban, N.C., Mills, M., Tam, J., Hicks, C.C., Klain, S., Stoeck1, N., Bottrill, M.C., Levine, J., Pressey, R.L., Satterfield, T., Chan, K.M., 2013. A social-ecological approach to conservation planning: embedding social considerations. Frontiers in Ecology and the Environment 11, 194-202. https://doi.org/10.1890/110205

Bennett, N.J., Roth, R., Klain, S.C., Chan, K.M.A., Clark, D.A., Cullman, G., Epstein, G., Nelson, M.P., Stedman, R., Teel, T.L., Thomas, R.E.W., Wyborn, C., Curran, D., Greenberg, A., Sandlos, J., Veríssimo, D., 2017. Mainstreaming the social sciences in conservation. Conservation Biology 31, 56-66. https://doi.org/10.1111/cobi.12788

Böhm, M., Collen, B., Baillie, J.E.M., Bowles, P., Chanson, J., Cox, N., Hammerson, G., Hoffmann, M., Livingstone, S.R., Ram, M., Afuang, L.E., Aghasyan, A., García, A., Aguilar, C., Ajtic, R., Akarsu, F., Alencar, L.R.V., Allison, A., Ananjeva, N., Anderson, S., Andrén, C., Ariano-Sánchez, D., Arredondo, J.C., Auliya, M., Austin, C.C., Avci, A., Baker, P.J., Barreto-Lima, A.F., Barrio-Amorós, C.L., Basu, D., Bates, M.F., Batistella, A., Bauer, A., Bennett, D., Böhme, W., Broadley, D., Brown, R., Burgess, J., Captain, A., Carreira, S., Castañeda, M. del R., Castro, F., Catenazzi, A., Cedeño-Vázquez, J.R., Chapple, D.G., Cheylan, M., Cisneros-Heredia, D.F., Cogalniceanu, D., Cogger, H., Corti, C., Costa, G.C., Couper, P.J., Courtney, T., Crnobrnja-Isailovic, J., Crochet, P.-A., Crother, B., Cruz, F., Daltry, J.C., Daniels, R.J.R., Das, I., de Silva, A., Diesmos, A.C., Dirksen, L., Doan, T.M., Dodd, C.K., Doody, J.S., Dorcas, M.E., Duarte de Barros Filho, J., Egan, V.T., El Mouden, E.H., Embert, D., Espinoza, R.E., Fallabrino, A., Feng, X., Feng, Z.-J., Fitzgerald, L., Flores-Villela, O., França, F.G.R., Frost, D., Gadsden, H., Gamble, T., Ganesh, S.R., Garcia, M.A., García-Pérez, J.E., Gatus, J., Gaulke, M., Geniez, P., Georges, A., Gerlach, J., Goldberg, S., Gonzalez, J.-C.T., Gower, D.J., Grant, T., Greenbaum, E., Grieco, C., Guo, P., Hamilton, A.M., Hare, K., Hedges, S.B., Heideman, N., Hilton-Taylor, C., Hitchmough, R., Hollingsworth, B., Hutchinson, M., Ineich, I., Iverson, J., Jaksic, F.M., Jenkins, R., Joger, U., Jose, R., Kaska, Y., Kaya, U., Keogh, J.S., Köhler, G., Kuchling, G., Kumlutaş, Y., Kwet, A., La Marca, E., Lamar, W., Lane, A., Lardner, B., Latta, C., Latta, G., Lau, M., Lavin, P., Lawson, D., LeBreton, M., Lehr, E., Limpus, D., Lipczynski, N., Lobo, A.S., López-Luna, M.A., Luiselli, L., Lukoschek, V., Lundberg, M., Lymberakis, P., Macey, R., Magnusson, W.E., Mahler, 
D.L., Malhotra, A., Mariaux, J., Marques, O.A.V., Márquez, R., Martins, M., Masterson, G., Mateo, J.A., Mathew, R., Mathews, N., Mayer, G., McCranie, J.R., Measey, G.J., Mendoza-Quijano, F., Menegon, M., Métrailler, S., Milton, D.A., Montgomery, C., Morato, S.A.A., Mott, T., Muñoz-Alonso, A., Murphy, J., Nguyen, T.Q., Nilson, G., Nogueira, C., Núñez, H., Orlov, N., Ota, H., Ottenwalder, J., Papenfuss, T., Pasachnik, S., Passos, P., Pauwels, O.S.G., Pérez-Buitrago, N., Pérez-Mellado, V., Pianka, E.R., Pleguezuelos, J., Pollock, C., Ponce-Campos, P., Powell, R., Pupin, F., Quintero Díaz, G.E., Radder, R., Ramer, J., Rasmussen, A.R., Raxworthy, C., Reynolds, R., Richman, N., Rico, E.L., Riservato, E., Rivas, G., da Rocha, P.L.B., Rödel, M.-O., Rodríguez Schettino, L., Roosenburg, W.M., Ross, J.P., Sadek, R., Sanders, K., Santos-Barrera, G., Schleich, H.H., Schmidt, B.R., Schmitz, A., Sharifi, M., Shea, G., Shi, H.-T., Shine, R., Sindaco, R., Slimani, T., Somaweera, R., Spawls, S., Stafford, P., Stuebing, R., Sweet, S., Sy, E., Temple, H.J., Tognelli, M.F., Tolley, K., Tolson, P.J., Tuniyev, B., Tuniyev, S., Üzüm, N., van Buurt, G., Van Sluys, M., Velasco, A., Vences, M., Veselý, M., Vinke, S., Vinke, T., Vogel, G., Vogrin, M., Vogt, R.C., Wearn, O.R., Werner, Y.L., Whiting, M.J., Wiewandt, T., Wilkinson, J., Wilson, B., Wren, S., Zamin, T., Zhou, K., Zug, G., 2013. The conservation status of the world's reptiles. Biological Conservation 157, 372-385. https://doi.org/10.1016/j.biocon.2012.07.015

Bonnet, X., Shine, R., Lourdais, O., 2002. Taxonomic chauvinism. Trends in Ecology \& Evolution 17, 1-3. https://doi.org/10.1016/S0169-5347(01)02381-3

Ceríaco, L.M., 2012. Human attitudes towards herpetofauna: The influence of folklore and negative values on the conservation of amphibians and reptiles in Portugal. Journal of Ethnobiology and Ethnomedicine 8, 8. https://doi.org/10.1186/1746-4269-8-8

Ceriaco, L.M.P., Marques, M.P., Madeira, N.C., Vila-Vicosa, C.M., Mendes, P., 2011. Folklore and traditional ecological knowledge of geckos in Southern Portugal: Implications for conservation and science. Journal of Ethnobiology and Ethnomedicine 7, 26. https://doi.org/10.1186/1746-4269-7-26

Chiszar, D., 1998. Herpetology, Critical Thinking, Curriculum Committees, and Disciplinary Fundamentalism. Herpetologica 54, S6-S11.

Clancy, K., Everett, K., Bacha, K., Hecht, K., Stofer, K.A., 2021. Lack of education and outreach publications in herpetology journals points to disconnect with human dimensions best practices. Manuscript in preparation.

Clucas, B., McHugh, K., Caro, T., 2008. Flagship species on covers of US conservation and nature magazines. Biodivers Conserv 17, 1517-1528. https://doi.org/10.1007/s10531008-9361-0

Davies, S.R., 2008. Constructing communication: talking to scientists about talking to the public. Science Communication 29, 413-434. https://doi.org/10.1177/1075547008316222

de Pinho, J.R., Grilo, C., Boone, R.B., Galvin, K.A., Snodgrass, J.G., 2014. Influence of aesthetic appreciation of wildlife species on attitudes towards their conservation in Kenyan agropastoralist communities. PLoS ONE 9, e88842. https://doi.org/10.1371/journal.pone.0088842

Demographic and Atmospheric Survey, 2020. . PARC Diversity, Equity, and Inclusion Task Team.

Dormann, C.F., Elith, J., Bacher, S., Buchmann, C., Carl, G., Carré, G., Marquéz, J.R.G., Gruber, B., Lafourcade, B., Leitão, P.J., Münkemüller, T., McClean, C., Osborne, P.E., Reineking, B., Schröder, B., Skidmore, A.K., Zurell, D., Lautenbach, S., 2013. 
Collinearity: a review of methods to deal with it and a simulation study evaluating their performance. Ecography 36, 27-46. https://doi.org/10.1111/j.1600-0587.2012.07348.x

Ecklund, E.H., James, S.A., Lincoln, A.E., 2012. How academic biologists and physicists view science outreach. PLOS ONE 7, e36240. https://doi.org/10.1371/journal.pone.0036240

Frost, D., 1998. Graduate education and natural history museums. Herpetologica 54, S17-S21.

Gangloff, E., 2011. Urban students and urban serpents: The effects of hands-on learning in student perception of snakes. Herpetological Review 42, 349-351.

Grant, E.H.C., Miller, D.A.W., Schmidt, B.R., Adams, M.J., Amburgey, S.M., Chambert, T., Cruickshank, S.S., Fisher, R.N., Green, D.M., Hossack, B.R., Johnson, P.T.J., Joseph, M.B., Rittenhouse, T.A.G., Ryan, M.E., Waddle, J.H., Walls, S.C., Bailey, L.L., Fellers, G.M., Gorman, T.A., Ray, A.M., Pilliod, D.S., Price, S.J., Saenz, D., Sadinski, W., Muths, E., 2016. Quantitative evidence for the effects of multiple drivers on continentalscale amphibian declines. Scientific Reports 6. https://doi.org/10.1038/srep25625

Gratwicke, B., Lovejoy, T.E., Wildt, D.E., 2012. Will Amphibians Croak under the Endangered Species Act? BioScience 62, 197-202. https://doi.org/10.1525/bio.2012.62.2.13

Gregory, R., Failing, L., Harstone, M., Long, G., McDaniels, T., Ohlson, D., 2012. Structured Decision Making: A Practical Guide to Environmental Management Choices. John Wiley \& Sons.

Gunnthorsdottir, A., 2001. Physical attractiveness of an animal species as a decision factor for its preservation. Anthrozoös 14, 204-215. https://doi.org/10.2752/089279301786999355

Hecht, K., 2021. A mixed-methods investigation of herpetologists' public engagement (Dissertation). University of Florida, Gainesville, FL.

Heckman, J.J., 1990. Selection Bias and Self-selection, in: Eatwell, J., Milgate, M., Newman, P. (Eds.), Econometrics, The New Palgrave. Palgrave Macmillan UK, London, pp. 201-224. https://doi.org/10.1007/978-1-349-20570-7_29

Hoehl, S., Hellmer, K., Johansson, M., Gredebäck, G., 2017. Itsy bitsy spider...: Infants react with increased arousal to spiders and snakes. Front. Psychol. 8. https://doi.org/10.3389/fpsyg.2017.01710

IUCN, 2018. The IUCN Red List of Threatened Species Summary Statistics. Version 2018-1. Jimenez, J.N., Lindemann-Matthies, P., 2015. Public Knowledge and Perception of Toads and Frogs in Three Areas of Subtropical Southeast China. Society \&amp; Animals 23, 166192. https://doi.org/10.1163/15685306-12341368

Knight, A.J., 2008. "Bats, snakes and spiders, Oh my!” How aesthetic and negativistic attitudes, and other concepts predict support for species protection. Journal of Environmental Psychology 28, 94-103. https://doi.org/10.1016/j.jenvp.2007.10.001

Knight, A.T., Cowling, R.M., Campbell, B.M., 2006. An operational model for implementing conservation action. Conservation Biology 20, 408-419. https://doi.org/10.1111/j.15231739.2006.00305.x

LoBue, V., DeLoache, J.S., 2008. The snake in the grass: attention to fear-relevant stimuli by adults and young children. Psychological Science 19, 284-289. https://doi.org/10.1111/j.1467-9280.2008.02081.X

Mascia, M.B., Brosius, J.P., Dobson, T.A., Forbes, B.C., Horowitz, L., McKean, M.A., Turner, N.J., 2003. Conservation and the social sciences. Conservation Biology 17, 649-650. https://doi.org/10.1046/j.1523-1739.2003.01738.x

Meffe, G.K. (Ed.), 2002. Ecosystem Management: Adaptive, Community-Based Conservation. Island Press, Washington, D.C. 
Morgan, J.M., Gramann, J., 1989. Predicting effectiveness of wildlife education programs: A study of students' attitudes and knowledge toward snakes. Wildlife Society Bulletin 17, 501-509.

O’Donnell, R.P., Durso, A.M., 2014. Harnessing the power of a global network of citizen herpetologists by improving citizen science databases. Herpetological Review 45, 151157.

Perry-Hill, R., Smith, J.W., Reimer, A., Mase, A.S., Mullendore, N., Mulvaney, K.K., Prokopy, L.S., 2014. The influence of basic beliefs and object-specific attitudes on behavioural intentions towards a rare and little-known amphibian. Wildlife Research 41, 287. https://doi.org/10.1071/WR13218

Pew Research Center, 2015. How Scientists Engage the Public.

Prokop, P., Tunnicliffe, S.D., 2010. Effects of having pets at home on children's attitudes toward popular and unpopular animals. Anthrozoös 23, 21-35. https://doi.org/10.2752/175303710X12627079939107

Rao, A., 2016. Attitudes towards outreach within the particle-physics research community. Proceedings for the 2016 Public Comminication of Science and Technology Conference. https://doi.org/10.5281/zenodo.60214

Reimer, A., Mase, A., Mulvaney, K., Mullendore, N., Perry-Hill, R., Prokopy, L., 2014. The impact of information and familiarity on public attitudes toward the eastern hellbender: Attitudes toward a rare salamander. Animal Conservation 17, 235-243. https://doi.org/10.1111/acv.12085

Reynolds, B.R., Salamander, T., Wilson, T.P., 2018. A walk in the woods: changing student attitudes toward amphibians and reptiles. Creative Education 09, 182-191. https://doi.org/10.4236/ce.2018.92014

Rommel-Crump, R., Crump, P., Packard, J., 2016. Leaping from awareness to action: impacts of an amphibian educator workshop. Journal of Herpetology 50, 12-16. https://doi.org/10.1670/14-025

Royal Society, 2006. Survey of factors affecting science communication by scientists and engineers. (Final Report). Royal Society, London, England.

Saunders, C.D., Brook, A.T., Myers, O.E., 2006. Using psychology to save biodiversity and human well-being. Conservation Biology 20, 702-705. https://doi.org/10.1111/j.15231739.2006.00435.x

Southwestern Center for Herpetological Research, 2017. Special Publication No. 2: 2015 Reptile and Amphibian Public Opinion Survey. (No. Final Report).

Tarrant, J., Kruger, D., du Preez, L.H., 2016. Do public attitudes affect conservation effort? Using a questionnaire-based survey to assess perceptions, beliefs and superstitions associated with frogs in South Africa. African Zoology 51, 13-20. https://doi.org/10.1080/15627020.2015.1122554

Tomažic, I., 2011. Pre-Service Biology Teachers' and Primary School Students' Attitudes Toward and Knowledge about Snakes. EURASIA Journal of Mathematics, Science \& Technology Education, 7, 161-171.

Wake, M.H., 2008. "eye of newt and toe of frog": herpetology in 21st century science. Herpetologica 64, 1-11. https://doi.org/10.1655/07-055.1

Weber, D., Schuett, G., Tluczek, M., 2016. A citizen science survey of the herpetofauna of Scottsdale's McDowell Sonoran Preserve, Arizona, USA. Herpetological Review 47, 5 10 . 
Whitehead, J.C., 1991. Environmental interest group behavior and self-selection bias in contingent valuation mail surveys. Growth and Change 22, 10-20. https://doi.org/10.1111/j.1468-2257.1991.tb00538.x

Wilson, K.A., Underwood, E.C., Morrison, S.A., Klausmeyer, K.R., Murdoch, W.W., Reyers, B., Wardell-Johnson, G., Marquet, P.A., Rundel, P.W., McBride, M.F., Pressey, R.L., Bode, M., Hoekstra, J.M., Andelman, S., Looker, M., Rondinini, C., Kareiva, P., Shaw, M.R., Possingham, H.P., 2007. Conserving biodiversity efficiently: what to do, where, and when. PLoS Biology 5, e223. https://doi.org/10.1371/journal.pbio.0050223

Wojnowski, D., 2008. Traditional and scientific conceptions of snakes in Kenya: Alternative perspectives for teaching (Dissertation). Kent State University.

Table 1. Stepwise model selection for

\begin{tabular}{lcr}
\hline Model & Parameters & AIC \\
\hline All subfields & 9 & 425.58 \\
Removed ecology & 8 & 423.60 \\
Removed physiology & 7 & 422.12 \\
Removed evolution & 6 & 420.50 \\
Removed human dimension & 5 & 419.51 \\
Removed morphology/anatomy & 4 & 419.20 \\
\hline
\end{tabular}

Table 2. Final results for model parameters of ordinal logistic regression measuring hours of engagement of respondent herpetologists by subfield

\begin{tabular}{lcrrrrr}
\hline & Value & $\begin{array}{c}\text { Std. } \\
\text { Error }\end{array}$ & t value & $\begin{array}{c}p \\
\text { value }\end{array}$ & $\begin{array}{r}\text { Odds } \\
\text { ratio }\end{array}$ & $95 \% \mathrm{Cl}$ \\
\hline $\begin{array}{l}\text { Conservation } \\
\quad \text { Biology }\end{array}$ & 0.752 & 0.342 & 2.199 & 0.03 & 2.118 & $1.088-4.170$ \\
Taxonomy & & & & & & \\
Behavior & 0.833 & 0.359 & 2.319 & 0.02 & 0.939 & $1.430-4.687$ \\
Education & 0.682 & 0.297 & 2.299 & 0.02 & 0.765 & $1.111-3.561$ \\
& 1.114 & 0.569 & 1.958 & 0.05 & 1.309 & $0.988-9.348$ \\
\hline
\end{tabular}


bioRxiv preprint doi: https://doi.org/10.1101/2021.05.14.444251; this version posted May 17, 2021. The copyright holder for this preprint (which

was not certified by peer review) is the author/funder, who has granted bioRxiv a license to display the preprint in perpetuity. It is made available under aCC-BY-NC-ND 4.0 International license.

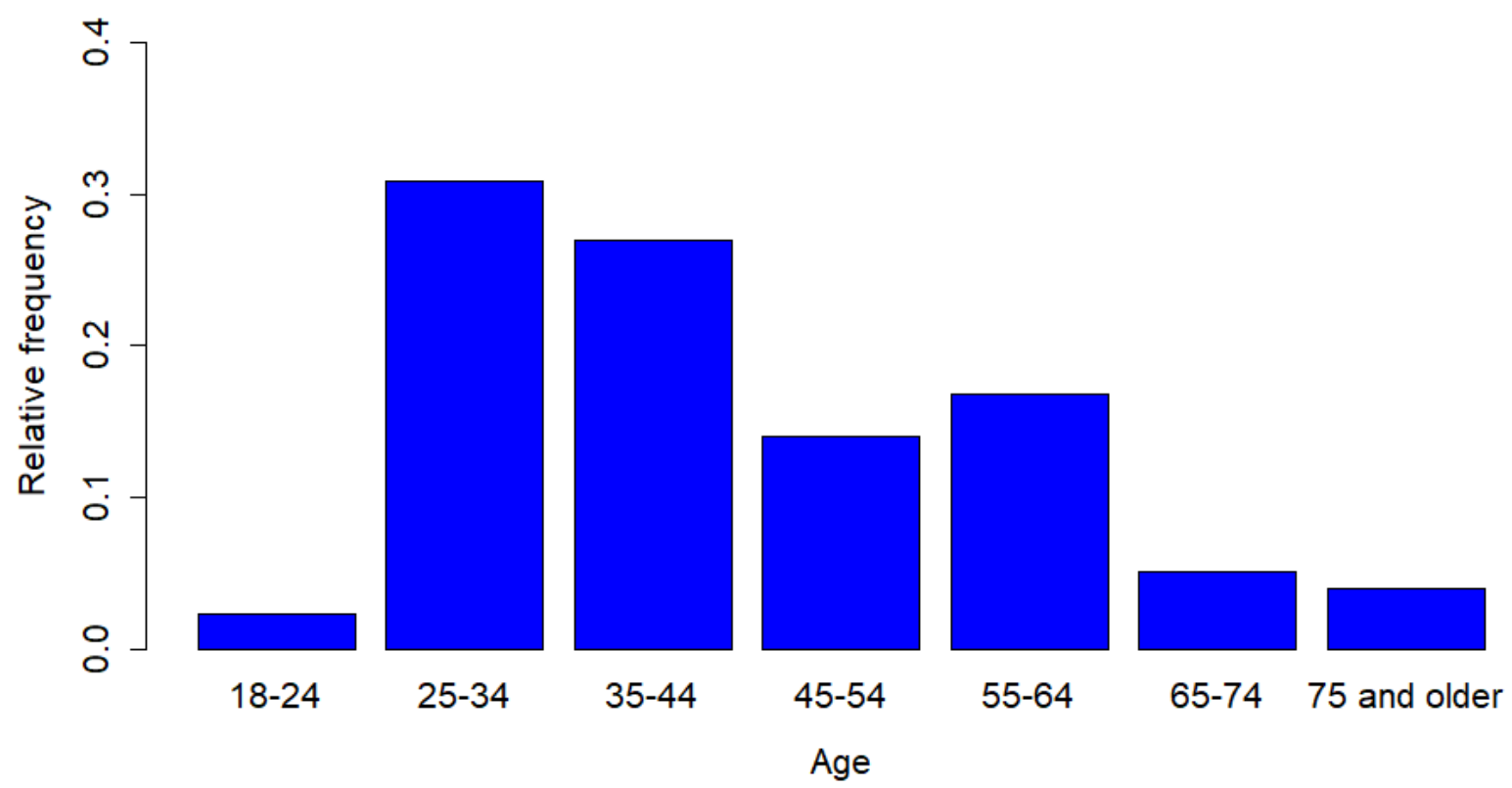

715 Figure 1. Age distribution of respondent herpetologists. 
bioRxiv preprint doi: https://doi.org/10.1101/2021.05.14.444251; this version posted May 17, 2021. The copyright holder for this preprint (which

was not certified by peer review) is the author/funder, who has granted bioRxiv a license to display the preprint in perpetuity. It is made available under aCC-BY-NC-ND 4.0 International license.

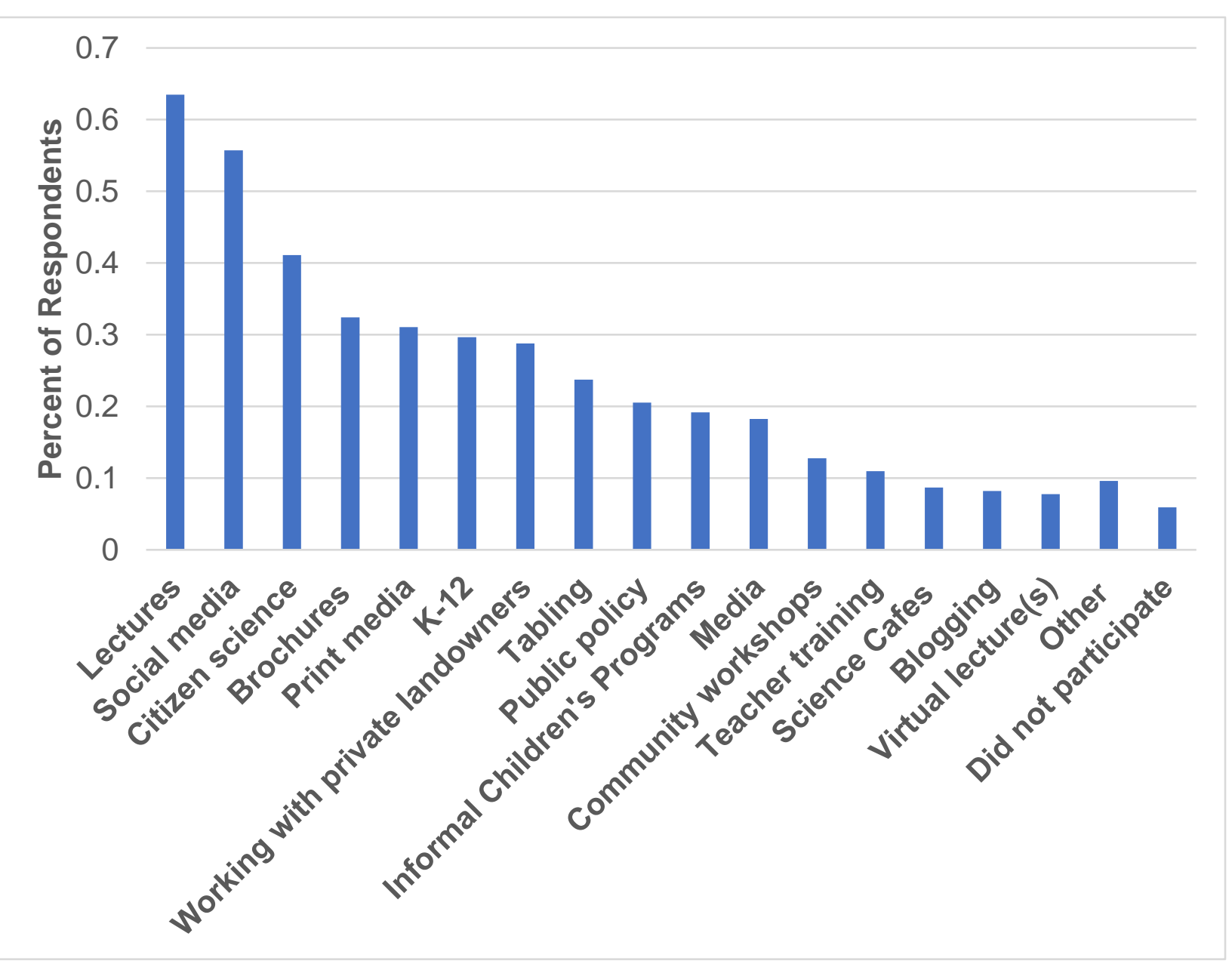

Figure 2. Types of public activities undertaken by respondent herpetologists within the past 12 months. 


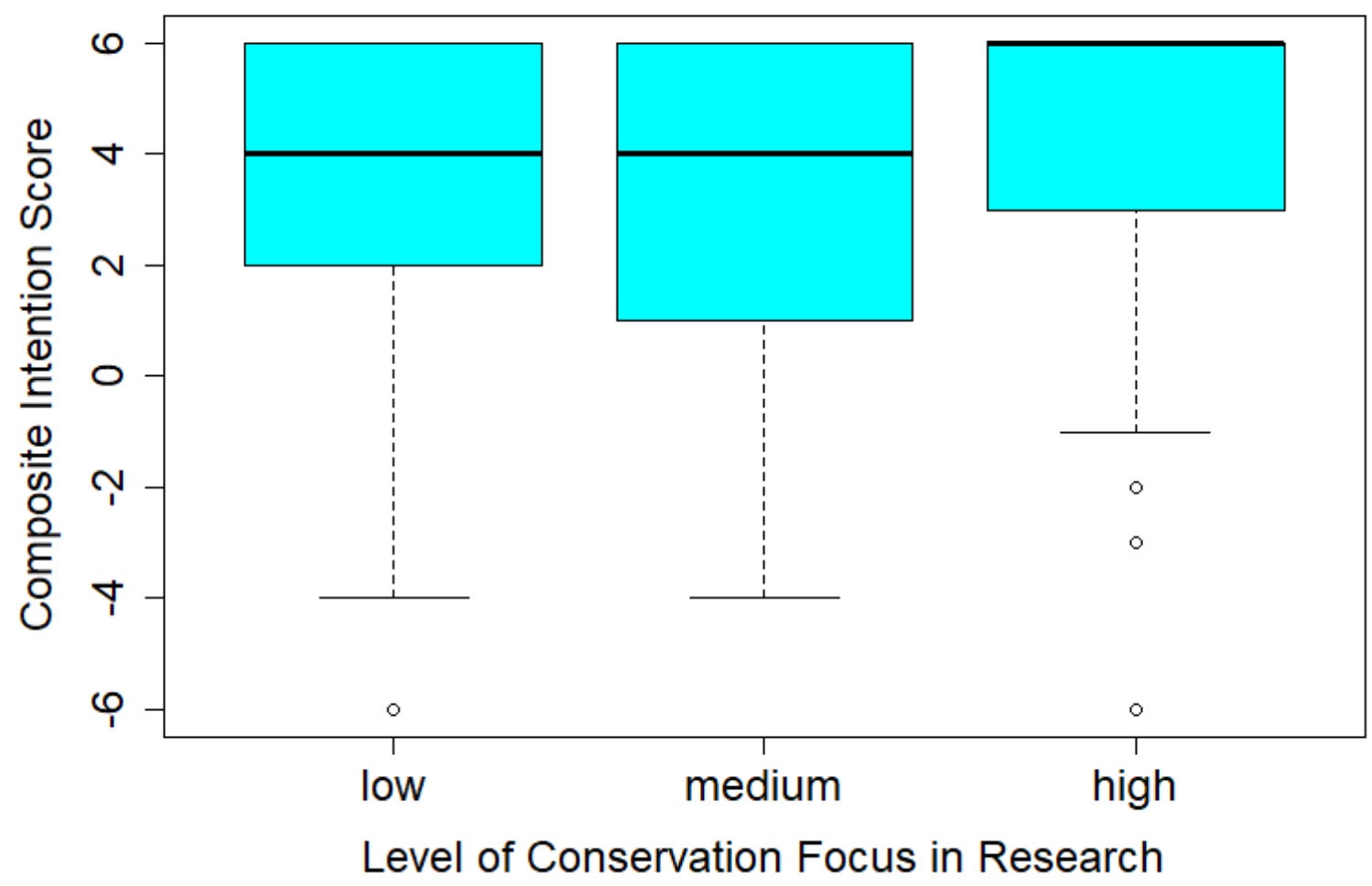

Figure 3. Boxplot of low $(n=55)$, medium $(n=23)$, and high $(n=100)$ levels of conservation focus in sampled herpetologists' research vs their intention to participate in public engagement for at least 10 hours over the next 12 months. 